\title{
O "Cavalo de Tróia" de Michel Pêcheux: uma breve reflexão sobre a análise automática do discurso
}

\author{
The "Troy's Horse" of Michel Pêcheux: a brief reflection \\ about the automatic analysis of discourse
}

Edmeire Cristina PEREIRA'

RESUMO

Este artigo discute a importância do pioneirismo de Michel Pêcheux para a Análise do Discurso francesa, considerando o seu pensamento a partir do texto Análise Automática do Discurso - AAD-69. Seu objetivo é aproximar alguns conceitos da análise documentária com a análise do discurso, preocupando-se com a questão da ideologia em análise de textos para fins documentais em Ciências e Gestão da Informação.

Palavras-chave: análise do discurso; Michel Pêcheux; análise automática do discurso.

\section{A B S TRACT}

This paper discusses the importance of Michel Pêcheux for the French Analysis of Discourse, considering his thoughts in the pioneer text Automatic Analysis of discourse - AAD-69. The objective of this study is to approximate some concepts of Documentary Analysis to Discourse Analysis, taking into consideration the ideology matter in text analysis for documentary purposes in Sciences and Information Management

Keywords: Discourse analysis; Michel Pêcheux; automatic analysis of discourse.

\section{NTRODUÇÃ O}

Sabe-se que a análise de texto torna-se hoje legítimo método de pesquisa em ciências sociais, denominado análise do discurso (Salomon, 1991, p.57). Esse tipo de análise é, atualmente, uma atividade especializada da lingǘstica e da literatura, cujos objetivos extrapolam os de disciplinas como metodologia do trabalho científico. Nesse caso, em se tratando, sobretudo, de trabalhos acadêmicos, a análise de texto se faz como um componente importante do ato de ler e do exercício da crítica, ao se realizarem os três tipos de atividades propostos por Bloom, quais sejam: a análise de elementos; a análise de relações e a análise de estrutura (Salomon, 1991, p.57).

\footnotetext{
1 Professora Assistente III, Departamento de Ciência e Gestão da Informação Universidade Federal do Paraná. Av. Prefeito Lothário Meissner, 632, Jardim Botânico, 80210-170,Curitiba, PR, Brasil. E-mail: <edmeire@ufpr.br>.

Recebido em 26/9/2006 a aceito para publicação em 30/5/2007.
} 
Por conseguinte, a análise do discurso ou análise de discursos é uma prática e um campo da lingüística e da comunicação especializado em analisar construções ideológicas presentes num texto. É muito utilizada, por exemplo, para analisar textos da mídia e as ideologias que trazem em si. A análise do discurso é proposta a partir da filosofia materialista que põe em questão a prática das ciências humanas e a divisão do trabalho intelectual, de forma reflexiva.

Posto isso, nosso interesse pelo tema vem de algumas aulas em nosso curso de mestrado em Biblioteconomia e Ciências da Informação (CAPES/ MINTER/PUC-Campinas e UFPR, no período de 1999 a 2001) sobre classificação e indexação e análise do discurso francesa, à época, ministradas pelas docentes Nair Y. Kobashi (2001) e Else B. M. Válio.

Dos conhecimentos recebidos naquela ocasião e a par da coincidência de objetivos entre a Análise Documentária e a Análise de Conteúdo, não é nosso interesse neste artigo embrionário, ainda, esmiuçar as aproximações e os recuos entre uma e outra. Temos, porém, interesse no estudo da aproximação entre os conceitos de Análise Documentária e Análise do Discurso, no que diz respeito à descrição dos discursos sobre Terminologia em Ciências da Informação, mormente em Gestão da Informação, nossa área de atuação. A razão principal é por entendermos que estamos diante de um paradoxo, ou seja: como "equalizar" a Análise Documentária ou Indexação de documentos com a Análise do Discurso, visto que a primeira é "disciplina de natureza metodológica" e não se preocupa com as condições sócio-históricas da produção discursiva, e a segunda dispõe de teorias e métodos para analisar as construções ideológicas presentes num texto e se preocupa com a conjuntura do sujeito, ou seja: acontecimentos, cenários, atores, relações de força e articulação entre estrutura e conjuntura? Ou, ainda, o que pensar da definição internacional da ISO 214-1976 (F), n.2, Definiciones sobre o termo Análise, que, para essa norma, significa: "uma representação abreviada e precisa do conteúdo de um documento, sem interpretação ou crítica"? (International..., 1976).

Daí que, pelas leituras realizadas, voltamo-nos para os estudos de Michel Pêcheux sobre análise automática do discurso, porque tomamos conhecimento de que, dos autores ocidentais da contemporaneidade, ele esteve entre os primeiros estudiosos que se preocuparam com a ideologia nos e dos sistemas de informação documentária, ou seja, preocupou-se com a historicidade dos textos em análise, pois, como sabemos, a ideologia nas análises de textos serve ou para conscientizar ou para alienar. Ou dito de outra maneira: ou serve para "literalizar sentidos ou interpretálos".

Este texto, portanto, é uma tentativa teórica de compreender a componente ideologia (sujeito) em semiótica documental (processo), na recuperação automática das informações pelos indexadores profissionais.

\section{Uma distinção prévia necessária...}

Em Biblioteconomia e Documentação, especificamente nos estudos sobre Indexação de documentos/informações, lidamos com os conceitos de: a) análise documentária; b) análise de conteúdo; c) análise do discurso. Explicitando melhor cada qual:

1) ANÁLISE DOCUMENTÁRIA (AD) - "Conjunto de procedimentos efetuados com o fim de expressar o conteúdo de documentos sob formas destinadas a facilitar a recuperação da informação" (Cunha, 1990, p. 59). Para a AD existem três linguagens interligadas: linguagem natural (LN); linguagens especializadas (LE); linguagens documentárias (LD). As hipóteses de Cunha (1990, p.72) eram a de que "a análise documentária e o seu produto são resultantes da ideologia do autor/ produtor, do analista e do sistema em que se encontram inseridos" e a de que "o seu novo-mito-modelo considera que grande parte dos erros da representação e transferência da informação se encontra na idéia de que o texto/discurso/documento é absoluto e passível de uma única leitura e, portanto, de uma única representação". Daí, a autora propor para a AD tanto elementos da análise de texto como de análise do discurso (Cunha, 1990, p. 139). Em seu "novo-modelomito", deve-se acabar com os pré-conceitos de texto "absoluto", "neutro", em favor de uma AD mais metodológica e pragmática. Este pensamento vai, inclusive, ao encontro do de Kobashi (1994) apud Lucas (2000, p.77): "define-se a análise documentária como uma disciplina de natureza metodológica que se preocupa com o tratamento do conteúdo dos textos". Finalmente, pode-se mencionar que Cunha (1990, 
p.66) difere a análise documentária da análise automática em termos de objetivos de recuperação da informação. Para tal, diz a autora, é necessário "colocar em equação as variáveis produtor, produção, contexto de produçãoX (versus) consumo e consumidor-usuário, ou seja, equacionar os vários sistemas em que se encontra inserida a informação contida no texto, a ser traduzida automaticamente".

2) ANÁLISE DE CONTEÚDO (AC) - “Conjunto de técnicas destinadas a ressaltar o conteúdo de diversas categorias de documentos escritos, certos elementos singulares de onde se inferem características psicossociológicas do objeto analisado". (Gardin, 1974, apud Cunha, 1990, p.62). "[...] nome convencional dado a toda espécie de estudos de textos destinados a esclarecer as questões relativas aos produtores de textos e seus consumidores". (Gardin, 1974, apud Cunha, 1990, p.62). Por ex.: análises de conteúdo, literárias, semióticas e lingüísticas, realizadas quer manualmente, quer de forma automática. Martins e Lintz (2000, p.5556) sintetizam assim a Análise de Conteúdo:

\footnotetext{
"Trata-se de uma técnica para estudar e analisar a comunicação de maneira objetiva, sistemática e quantitativa. [...] A análise de conteúdo pode ser aplicada virtualmente a qualquer forma de comunicação: programas de televisão, rádio, artigos da imprensa, livros, poemas, conversas, discursos, cartas, regulamentos etc. [...]" Dentre os inúmeros usos da análise de conteúdo, há o desvendamento das ideologias dos dispositivos legais. Quanto ao processo de análise de conteúdo, são três as suas etapas: 1) pré-análise: coleta e organização do material a ser analisado; 2) descrição analítica: estudo aprofundado do material, orientado pelas hipóteses e referencial teórico. Escolha das unidades de análises (a palavra, o tema, a frase, os símbolos etc). Essas unidades são juntadas segundo algum critério e definem as categorias. Por exemplo, um discurso poderia ser classificado como otimista ou pessimista, como liberal ou conservador. As categorias devem ser exaustivas e mutuamente excludentes. Das análises de freqüências das categorias surgem quadros de referências; 3) análise de resultados: com os quadros de referência, os conteúdos (manifesto e latente) são revelados em função dos propósitos do estudo.
}

3) ANÁLISE DO DISCURSO (ADI) - Esta análise compreende a natureza social do discurso, isto é, compreende a historicidade do texto. A ADI de origem francesa vê nos textos os "conteúdos" da História. (Válio; Oliveira, 2003, p. 115). Para Orlandi, "A análise do discurso trata da questão da interpretação, restituindo a espessura à linguagem e a opacidade aos sentidos. Ela propõe, então, uma distância, uma desautomatização da relação do sujeito com os sentidos". (1996, p.90). Segundo Pêcheux, o sentido de uma palavra muda de acordo com a formação discursiva a que pertence. Para ele, "[...] é impossível analisar um discurso como um texto, isto é, como uma seqüência lingüistica fechada sobre si mesma, mas que é necessário referi-lo ao conjunto de discursos possíveis a partir de um estado definido das condições de produção [...]" (Gadet; Hak, 1993, p.79).

Para Pêcheux (1993, p. 104-105):

um discurso não apresenta, na sua materialidade textual, uma unidade orgânica em um só nível que se poderia colocar em evidência a partir do próprio discurso, mas que toda forma discursiva particular remete necessariamente à série de formas possíveis, e que essas remissões da superfície de cada discurso às superfícies possíveis que lhe são (em parte) justapostas na operação de análise constituem justamente os sintomas pertinentes do processo de produção dominante que rege o discurso submetido à análise.

Maingueneau (1989) apud Lucas (2000, p.45) observa que, enquanto a análise do conteúdo percorre os textos para decodificá-los, a análise do discurso exige uma outra forma de leitura. Pêcheux (1990) apud Lucas $(2000$, p.45) vem explicitar com clareza o que deseja esta leitura:

A análise de discurso não pretende se instituir como especialista da interpretação, dominando "o" sentido dos textos; apenas pretende construir procedimentos que exponham o olhar-leitor a níveis opacos à ação estratégica de um sujeito [...]. O desafio crucial é o de construir interpretações, sem jamais neutralizálas, seja através de uma minúcia qualquer de um discurso sobre o discurso, seja no espaço lógico estabilizado com pretensão universal. 
Acreditamos que essa distinção conceitual acima é muito importante para o nosso trabalho porque tem a ver com a definição dos termos texto e discurso, tomados aqui neste artigo NÃO como sinônimos, porque o primeiro refere-se, basicamente, a um conjunto de palavras, frases escritas; enquanto que o segundo diz respeito às diferentes falas, a quaisquer manifestações concretas das línguas, em sentido lato. Já no sentido estrito do termo, emprestamos de Izquierdo Arroyo (1993, p.201-202) o seu entendimento para os termos: "texto - escrito ou oral - como a representação física do discurso e discurso como o plano do conteúdo de um texto". Segundo esse autor, inclusive, como a lingüística não cobre a totalidade dos signos, há uma preferência em se referir à semiótica. Daí a preferência por "semiótica do discurso", ao invés de "semiótica do texto" (Izquierdo Arroyo, 1993, p.203). Ou, indo um pouco mais adiante: a semiótica do discurso dá passo à semiótica documental, ocupada com o tratamento documental do conteúdo, como núcleo ótimo para investigação (Izquierdo Arroyo, 1993, p.204).

\section{Estabelecendo limites entre os termos texto e discurso e texto e documento}

Para o trabalho com indexação documentária, faz-se mister conhecer os gêneros textuais (se argumentativos, narrativos ou descritivos) para, então, escolher os seus constituintes de indexação. Para Guimarães (1990, p.43), a organização dos textos dáse pela articulação de seus elementos temáticos com os elementos estruturais. Para essa autora, as noções de forma e função evocam a noção de estrutura, isto é, a rede de dependências e implicações que um elemento mantém com todos os outros, no conjunto em que se encontra. Assim, do ponto de vista estrutural, a autora refere-se a todo o texto quando o diz narrativo, dissertativo ou descritivo - a superestrutura determinando a ordem (a coordenação) global das partes do texto (Guimarães, 1990, p.64-65).

A característica fundamental do texto narrativo é, entretanto, sua referência primordial a ações de pessoas, às quais as descrições de circunstâncias e objetos ficam subordinadas (Guimarães, 1990, p.67). Quanto ao texto dissertativo, mais do que qualquer outro, é um tipo de organização de linguagem que requer rigorosa articulação de suas partes - uma sintonia perfeita entre premissas e conclusão (Guimarães, 1990, p.73). Por fim, o texto descritivo articula-se em torno de: um tema-chave, uma série de subtemas e de expansões predicativas (Guimarães, 1990, p.73).

Esses exemplos são relevantes para os indexadores porque o tempo todo eles estarão fazendo o processamento de informações, por meio de análises/ sínteses/representações. Esses profissionais, ao desempenharem a função de gestores de documentos, estarão preocupados em classificar o seu acervo, em organizar os seus estoques de conhecimento, usando de parâmetros modernos, tais como os metadados; ao passo que, os gestores de informações terão por preocupação primeira, os conteúdos (que são apenas uma parte dos metadados). Discutimos mais detalhadamente essa questão das hipóteses de organização dos instrumentos de representação da informação em outro artigo, intitulado Princípios de organização e representação de conceitos em linguagens documentárias, publicado no periódico Encontros Bibli, de Santa Catarina, Edição de n.20, de Outubro de 2005 (Pereira; Bufrem, 2005).

Ainda, a propósito do termo texto, Guimarães (1990, p. 14-15) o define como segue:

\begin{abstract}
A palavra texto designa um enunciado qualquer, oral ou escrito, longo ou breve, antigo ou moderno. Concretiza-se, pois, numa cadeia sintagmática de extensão muito variável, podendo circunscrever-se tanto a um enunciado único ou a uma lexia quanto a um segmento de grandes proporções. São textos, portanto, uma frase, um fragmento de um diálogo, um provérbio, um verso, uma estrofe, um poema, um romance, e até mesmo uma palavra-frase, ou seja, a chamada frase de situação ou frase inarticulada, como a que se apresenta em expressões como "Fogo!", "Silêncio", situadas em contextos específicos. Quando não limitado às fronteiras da linguagem verbal, no plano semiótico, de sentido multidimensional, texto ou discurso é sinônimo de processo que engloba as relações sintagmáticas de qualquer sistema de signos. Pode-se então falar de texto ou discurso cinematográfico, teatral, coreográfico, pictórico etc.
\end{abstract}

Para McGarry (1999, p. 127), “O vocábulo texto deriva do verbo latino texere, tecer e, portanto, refere- 
se não a um material específico como tal, mas ao seu estado de tecido, à trama e textura dos materiais". $\bigcirc$ autor continua sua explicação sobre o termo, assim: "Podemos considerar o texto como um tecido intelectual de signos numa unidade coerente e o documento como substrato físico, bem à maneira da computação neural, que considera a mente como o software e o cérebro como substrato material. Isso nos permite dizer: Você danificou o documento, mas felizmente o texto está intacto". Com esse pensamento do autor, agrega-se mais um componente para reflexão. Desta vez, é o termo documento, que é entendido como qualquer registro gráfico ou substrato material de um texto. A NBR12676/92 o define como: "Qualquer unidade, impressa ou não, que seja passível de catalogação ou indexação" (Associação..., 1992).

Na perspectiva dos discursos, a relação autor/ leitor e produção de sentidos, ajusta-se à classificação dos discursos como: discurso autoritário (o autor pretende fazer o leitor fazer); discurso factivo (o autor pretende fazer o leitor ser); discurso científico (o autor pretende fazer o leitor saber) e o discurso persuasivo (o autor pretende fazer o leitor crer) (Guimarães, 1990, p.17-18).

Orlandi (1988) discute, na visão de Foucault e Pêcheux, o discurso, suas funções e formações. $\mathrm{Na}$ visão de Foucault, ele é uma "regularidade de uma prática". Tem como função assegurar a permanência de uma certa representação, pois na origem de todo discurso existe o projeto totalizante de um sujeito, projeto que o converte em autor. $\bigcirc$ sujeito é a peça central do discurso que, por sua vez, o constitui como autor. $\bigcirc$ discurso é o palco onde o sujeito se constitui como autor ao constituir o texto. Para a autora, não podemos confundir um texto com um discurso, pois o texto é a "unidade de análise do discurso: o enunciado é a unidade de construção do discurso, mas discurso apóiase no texto em seu processo de construção, apenas para estruturar-se" (Orlandi, 1988, p. 115).

A formação discursiva constitui-se, então, a partir de uma situação, dos fatos ocorridos na sociedade. Para Pillon e Cruz (1996) ela é "o lugar da constituição do sentido e da identificação do sujeito. A formação discursiva é o lugar em que todo o sujeito reconhecese e identifica-se, adquirindo sua própria identidade. E também o sentido adquire a sua unidade".

É por isso que, ao analisarmos o discurso científico, por exemplo, observamos que para a sua compreensão e interpretação necessitamos nos acercar de sua legitimação e dos sujeitos que nele se reconhecem através do jogo interativo entre autor/ conhecimento/sujeito cognitivo (Pillon; Cruz, 1996). Ou, ainda, entender que o discurso científico é um "discurso fechado" em termos de possibilidades interpretativas, porque requer uma sintonia fina entre premissas e conclusão (Guimarães, 1990, p.70-71; p.73).

Segundo Pêcheux, conforme já foi citado: "[...] é impossível analisar um discurso como um texto, isto é, como uma seqüência lingüística fechada sobre si mesma, mas que é necessário referi-lo ao conjunto de discursos possíveis a partir de um estado definido das condições de produção [...]" (Gadet; Hak, 1993, p. 79). Daí que o entendimento do termo ideologia se faz pertinente nessa análise. A ideologia comporta vários sentidos. Em um sentido amplo, é o conjunto de idéias, concepções ou opiniões sobre algum ponto sujeito à discussão (doutrina, posicionamento interpretativo diante de certos fatos). Por exemplo: ideologia liberal ou ideologia marxista. Pode ser vista, também, como teoria, no sentido de organização sistemática dos conhecimentos destinados a orientar uma ação efetiva, como por exemplo, a ideologia de uma escola, a ideologia religiosa, partidária etc. Já, em sentido restrito, segundo a concepção marxista, a ideologia adquire um sentido negativo, como instrumento de dominação. Tem caráter ilusório, insidioso. A definição de Chauí é preciosa:

A ideologia é um conjunto lógico, sistemático e coerente de representações (idéias e valores) e de normas ou regras (de conduta) que indicam e prescrevem aos membros da sociedade o que devem pensar e como devem pensar, o que devem valorizar, o que devem sentir e como devem sentir, o que devem fazer e como devem fazer. Ela é, portanto, um corpo explicativo (representações) e prático (normas, regras, preceitos) de caráter prescritivo, normativo, regulador, cuja função é dar aos membros de uma sociedade dividida em classes uma explicação racional para as diferenças sociais, políticas e culturais, sem jamais atribuir tais diferenças à divisão da sociedade em classes, a partir das divisões na esfera de produção. Pelo contrário, a função da ideologia é a de apagar as diferenças, como as de classes, e de fornecer aos membros da sociedade o sentimento da identi- 
dade social, encontrando certos referenciais identificadores de todos e para todos, como, por exemplo, a Humanidade, a Liberdade, a Igualdade, a Nação, ou o Estado (Aranha; Martins, 1995, p.37).

\section{Os fundamentos teóricos da Análise Automática do Discurso, de Michel Pêcheux (1969), por Paul Henry}

Em 1966, Michel Pêcheux publica seu primeiro texto: Réflexions sur la situation theórique des sciences sociales; na revista Cahiers pour l' analyse, que pertencia ao Cercle d'Epistemologie de l'Ecole Normale Supérieure, em Paris. Em 1968, publica outro texto, intitulado: Remarques pour une théorie générale des idéologies.

$\bigcirc$ curioso desses dois textos é que foram assinados por Thomas Herbert, um pseudônimo ou codinome de Michel Pêcheux. E, entre os anos de 1966 e 1968, publicou dois artigos sobre análise do discurso, desta vez assinados por ele mesmo. Oportunismo? Não, apenas uma estratégia cuidadosamente deliberada.

No primeiro texto, Herbert desenvolve uma análise precisa sobre o que é um instrumento científico; e é sobre esta base de análise que Pêcheux concebeu seu sistema de análise automática do discurso.

No início do segundo texto de Herbert encontramos um resumo dos resultados do primeiro. Nesse resumo são enunciadas duas proposições fundamentais. A primeira concerne às condições nas quais uma ciência estabelece seu objeto. A segunda, por sua vez, refere-se ao processo de "reprodução metódica" desse objeto, isto é, o processo por meio do qual uma ciência explora, do interior, seu próprio discurso, testando sua consistência e necessidade.

Para Michel Pêcheux: 1) Toda ciência é antes de tudo, a ciência da ideologia com a qual rompe. Logo, o objeto de uma ciência não é um objeto empírico, mas uma construção; 2) Em cada ciência, deve haver dois momentos: a) o momento da transformação produtora do seu objeto; b) o momento da "reprodução metódica" desse objeto, o qual é de natureza conceitual e experimental. Enfim, com seu primeiro texto, Pêcheux critica a concepção da prática científica, como continuidade das "práticas técnicas". Os dois textos de Herbert delineiam uma análise sobre as raízes históricas da epistemologia e da filosofia do conhecimento empiricista.

No segundo texto de Herbert, Pêcheux analisa a ideologia enquanto um processo com "dupla-face": processo de produção e relação sociais.

\section{Um instrumento científico}

A primeira publicação de Pêcheux diz respeito à situação teórica nas ciências sociais. E é um texto fundamental para se compreender aquilo que ele objetivava ao desenvolver a análise automática do discurso: fornecer às ciências sociais um instrumento científico. Para o autor: 1) $\bigcirc$ estado das ciências sociais era um tanto pré-científico; 2) $\bigcirc$ estabelecimento de uma ciência necessita de instrumentos. Pêcheux é um filósofo de formação, mas um filósofo fascinado pelas máquinas, pelas ferramentas, pelos instrumentos e pelas técnicas. Ele visava a uma transformação da prática nas ciências sociais, desejava uma prática verdadeiramente científica.

Michel Pêcheux estava convicto de que as ciências sociais não são ciências e são nada mais que ideologias. Para ele, uma única crítica válida a tais ideologias é uma ciência, ou as ciências, do terreno ou do domínio que elas ocupam. É isto precisamente o que ele quer dizer quando escreve que uma ciência é, antes de tudo, a ciência da ideologia (ou das ideologias) com as quais ele rompe. Ideologias para ele são procedências, entre as quais estão as ciências sociais.

A crítica feita por Pêcheux sobre a utilização de instrumentos nas ciências sociais é um ponto crucial. Daí ele ter concebido a sua análise automática do discurso como um instrumento.

\section{As ciências sociais e seus instrumentos}

Com seu primeiro texto, Pêcheux critica a concepção da prática científica, que a coloca na continuidade das "práticas técnicas". 
As ciências sociais, segundo Pêcheux, estão no prolongamento direto das ideologias que se desenvolveram em contato estreito com a prática política. Mas Pêcheux acrescenta ainda algo concernente à prática política, que, enfim, nos faz retornar à análise do discurso. Ele diz que o instrumento da prática política é o discurso, ou mais precisamente, que a prática política tem como função, pelo discurso, transformar as relações sociais reformulando a demanda social.

\section{Linguagem, discurso e ideologia}

Do ponto de vista de Pêcheux, as ciências sociais são essencialmente técnicas, e têm uma ligação crucial com a prática política e com as ideologias desenvolvidas em contato com tal prática, cujo instrumento é o discurso.

Pêcheux recusa completamente a concepção da linguagem que a reduz a um instrumento de comunicação de significações que existiriam e poderiam ser definidas independentemente da linguagem, isto é, informações.

\section{Estruturalismo da linguagem}

Pêcheux, não mais que Lacan, Foucault ou Althusser, não pode ser considerado um estruturalista.

Os estruturalistas identificaram cultura e linguagem de tal modo que toda análise de qualquer fato cultural devia tomar uma forma de análise lingüística, ou qualquer coisa de similar (semiologia, semiótica). No estruturalismo, os conceitos e os métodos lingüísticos foram simplesmente transferidos para outros campos sem ter sofrido reelaborações fundamentais.

\section{Sujeito, discurso e ideologia}

A preocupação principal de Pêcheux refere-se à ligação entre o discurso e a prática política, passando pela ideologia. E foi para expressar esta ligação que Pêcheux introduziu aquilo que ele chama discurso, tentando desenvolver uma teoria do discurso e um dispositivo operacional de análise do discurso. $\bigcirc$ discurso de Pêcheux não é o de Foucault (1971). O sujeito de Foucault é o sujeito da "ordem do discurso".

Michel Pêcheux foi aluno de Louis Althusser e não podia deixar de estar familiarizado com o pensamento lacaniano. Entretanto, nem Freud nem Lacan figuram na bibliografia da AAD. Daria para ser diferente? Penso que não. Por quê? Porque na época dos textos de Michel Pêcheux assinados por Thomas Herbert, ele permanece orientado para um horizonte teórico implicitamente dominado por um fantasma da articulação entre o materialismo histórico, consciente, contribuição regional. Ou seja, a Psicanálise era vista pela teoria marxista como ideologia "pequenoburguesa". Nesse caso, o papel dos sujeitos da época decorria da sua competência e não como resultado da divisão de classes. Outra inversão própria da ideologia é a divisão hierárquica entre o pensar e o agir, na qual um segmento mais privilegiado da sociedade se dedica ao trabalho intelectual e outro, ao trabalho manual. Portanto uma classe "sabe pensar" e decide, enquanto a outra classe "não sabe pensar" e só obedece.

\section{A teoria e a análise do discurso de Pêcheux}

Pêcheux colocou-se entre o que podemos chamar de:

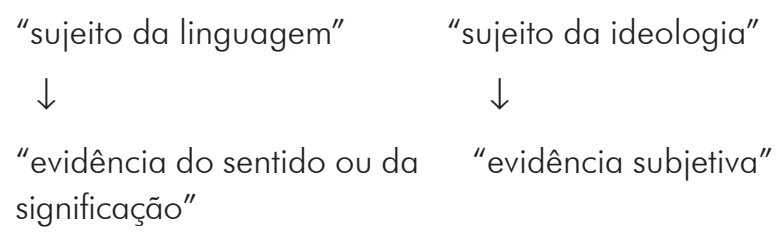
significação"

Ele voltou sua atenção para outro problema: o das ligações entre o objeto da análise e da teoria do discurso e o objeto da lingüística.

Pêcheux nunca abandonou esse problema da ligação ente o sujeito da linguagem e o da ideologia. Em seu último livro, escrito em conjunto com Françoise 
Gadet, ele ainda se ocupava da lingüística e de suas ambigüidades frente à disjunção entre aquilo que faz e o que não faz sentido, enquanto problema ao mesmo tempo teórico e político: "a metáfora merece que se lute por ela", escreve ele, citando Kundera. Os instrumentos científicos não são feitos para dar respostas, mas para colocar questões.

De certo modo, Michel Pêcheux concebeu seu sistema como uma espécie de "Cavalo de Tróia" destinado a ser introduzido nas ciências sociais para provocar uma reviravolta (algo análogo ao que Foucault tentou com sua "arqueologia" em relação à história das idéias). O que teria saído do "Cavalo de Tróia" de Pêcheux, então? Ao contrário do cavalo original da história helenística, de onde saíram os gregos, no nosso entendimento, do cavalo de Tróia de Pêcheux saiu um dispositivo de análise automática do processo discursivo.

Para os leitores que desconhecem a história do Cavalo de Tróia, ei-la:

Cavalo de madeira por meio do qual os gregos conseguiu penetrar em Tróia, cidade que lhes resistiu ao assédio durante dez anos. Os gregos construíram o cavalo aconselhados por Minerva e, em seu interior, esconderam um grande número de guerreiros. Deixaram-no junto às muralhas da cidade e fingiram partir. Em vão, a profetisa Cassandra e o sacerdote Laocoonte aconselharam seus compatriotas a não o recoIherem. Persuadidos por Sínon, que se fazia passar por desertor grego, os troianos puxaram o cavalo para dentro da cidade. À noite, os gregos saíram de seu interior, e saquearam e incendiaram Tróia (CASTRO, 1976, p.31).

quadro epistemológico de Pêcheux (Orlandi, 1996, p.108) rearticula-se em três regiões do conhecimento científico: o materialismo histórico, fundamentado na "teoria da ideologia"; a Lingüística, centrada na "teoria dos mecanismos sintáticos e dos processos de enunciação"; a Teoria do Discurso, que focaliza "a teoria da determinação histórica dos processos semânticos", incluindo-se aí, portanto, o estudo da Terminologia.

Somente para nos situar, Marchiori (2002, p. 97) lembra-nos que "Os estudos sobre informação implicam conhecimentos básicos da linguagem natural e formal, das classificações lingüísticas, da semântica, sintática e pragmática, por exemplo".

\section{Formalização e informática}

lugar destacado que a formalização ocupa na AAD-69 inscreve-se, para Michel Pêcheux, numa dupla perspectiva: epistemológica: por um lado, visando a definir procedimentos repetíveis e comparáveis que definam, de algum modo, heurísticas para a análise do discurso, operacional; por outro lado, permitindo obter resultados empíricos, de maneira a propor uma alternativa teórica e metodológica à análise de conteúdo. Trata-se, pois, para Michel Pêcheux, não somente de formalizar o dispositivo da AAD, mas de informatizá-lo. Essa formalização em Michel Pêcheux situa-se em um quadro essencialmente algébrico (teoria dos grafos) antes que lógico. Alguns empréstimos foram feitos igualmente ao domínio das gramáticas formais (autômatos a estados finitos, pilhas e listas). Todo o dispositivo, enfim, foi representado sob forma de algoritmos, diretamente admissível à programação informatizada desses últimos. Por outro lado, a investigação de uma automatização do dispositivo de análise do discurso cruzava-se com os trabalhos de Tradução Automática desenvolvidos, nessa época, na França, principalmente no CETA (Centre d'Etudes et de Traduction Automatique), em Grenoble, com o qual Pêcheux colaborou.

Na AAD-69, Michel Pêcheux situa-se no campo dos métodos de análise por computador, criticando os programas de lexicometria e de análise documental, tais como o programa SYNTOL (J.C.Gardin) ou o General Inquirer. $O$ programa AAD foi, juntamente com os programas de lexicometria, aperfeiçoado pela equipe de St. Cloud, um dos primeiros programas operacionais no domínio da análise de textos por computador. Três versões do programa foram realizadas:

1) $O$ programa AAD-69, escrito em Fortran IV por Michel Pêcheux e Ph.D Duval, foi implantado no Centre de Calcul pour les Sciences Humaines do CNRS, em 1972. Foi usado por duas dezenas de pesquisadores em Ciências Humanas, de 1971 a 1981. Isso 
mostra o interesse suscitado pela novidade da abordagem metodológica e teórica que o dispositivo AAD representava.

2) Pela progressiva inadequação do programa, Michel Pêcheux e sua equipe buscaram, a partir de 1980, uma alternativa a ele. 0 Software Deredec foi, então, programado por P. Plante, na Universidade de Quebec, em Montreal. Esse software oferecia novas perspectivas de análise automática do discurso.

3) Programa AAD-69 foi igualmente implantado na Universidade de Quebec, em Montreal e em Madri, graças a N. Pizarro.

4) Duas versões do dispositivo AAD também foram implantadas na Universidade de Grenoble II, por causa do vínculo que Pêcheux mantinha com seus pesquisadores.

5) A versão AAD foi realizada em ALGOLW por Ph.D Bizard e M. Dupraz, em 1972.

6) Uma versão posterior (1975), nomeada AAD75, foi realizada em Algolw por C. Del Vigna.

Coube ao próprio Pêcheux uma epítome de seus estudos sobre AAD, em três épocas: I - A primeira época da análise de discurso: AD-1 como exploração metodológica da noção de maquinaria discursivoestrutural, cuja conclusão é a seguinte: AD-1 é um procedimento por etapa, com ordem fixa, restrita teórica e metodologicamente a um começo e um fim predeterminados, e trabalhando num espaço em que as "máquinas" discursivas constituem unidades justapostas. A existência do outro está, pois, subordinada ao primado do mesmo [...]. II - AD-2: da justaposição dos processos discursivos à tematização de seu entrelaçamento desigual: do ponto de vista dos procedimentos, AD-2 manifesta muito poucas inovações: o deslocamento é sobretudo sensível ao nível da construção dos corpora discursivos, que permitem trabalhar sistematicamente suas influências internas desiguais, ultrapassando o nível da justaposição contrastada. III - A emergência de novos procedimentos da $A D$, por meio da desconstrução das maquinarias discursivas: AD-3. Seria inútil pretender descrever como um objeto este que se tenta hoje: apenas se pode procurar falar do interior dessa tentativa. Indicar algumas direções referíveis em um trabalho de interrogação-negação-desconstrução das noções postas em jogo na $A D$, mostrar alguns fragmentos de construções novas. (Pêcheux, 1983, apud Gadet; Hak, 1993, p.311-318).

A semântica formal é composta de teorias sobre significação. Uma dessas teorias é a DRT (Discourse Representation Theory), criada nos anos 80. Na DRT, textos são representados por estruturas denominadas DRS (Discourse Representation Structures), que são esquemas de representação de discurso - espécies de caixas em que são colocados dois tipos de conjuntos: um conjunto de referentes do discurso, chamado de universo da DRS, e um conjunto de condições que esses referentes devem satisfazer. Por exemplo, na sentença "Pedro corre", o indivíduo "Pedro" é denotado pelo referente " $x$ " que satisfaz a condição "corre $(x)^{\text {". As }}$ DRS são ferramentas úteis na interpretação formal das línguas naturais e a DRT tem se mostrado uma teoria poderosa na compreensão do fenômeno da formação de sentenças em linguagem natural, o que tem despertado o interesse de estudiosos ligados ou à lingüística ou à pesquisa sobre inteligência artificial (Beccari, 2003, p. 112 ).

\section{(IN) C O N C L US Ã O}

Buscamos nos autores enumerados abaixo mais um aporte para o fecho deste artigo, sem a pretensão de emitir uma conclusão definitiva sobre a questão da análise automática do discurso, porque entendemos que, em Ciências da Informação, as discussões não são abundantes, em língua portuguesa, em se tratando de ideologia em semiótica documental:

1) Cunha (1990, p.20):

Em relação aos teóricos da Biblioteconomia/ Documentação não encontramos na escola francesa grandes preocupações pelo assunto que nos propomos a discutir. Se os franceses, nomeadamente, Chaumier, Coyaud e Pêcheux trabalham com a análise documentária, eles o fazem em nível das "receitas". Isto é, dão-nos as fórmulas do fazer sem nos apresentarem os problemas que thes são inerentes. Talvez Pêcheux, ao trabalhar com análise automática, 
no seu texto de 1975, seja o único a colocar interrogações, principalmente no que toca às ideologias nos e dos sistemas de informação documentária.

2) García Gutierrez (1992, p.33) apud Alcaide et al. (2001, p.27):

\begin{abstract}
Nos anos 60 surgiram "modelos de representação automática" baseados na leitura seqüencial do texto; o autor afirma que em tais modelos predominam a representação sobre a análise. Os textos da Ciência da Informação abordam a existência de subjetividade no processo de indexação automática, porém não esclarecem/propõem uma sistematização analítica.
\end{abstract}

3) Role (1993, p. 140) apud Alcaide et al. (2001, p.27): Também se opõe à indexação automática, dizendo que os sistemas informatizados não realizam nenhuma espécie de análise, mas trabalham somente com a extração de palavras do texto.

4) Maingueneau (1993, p. 188), é contundente em suas conclusões, ao afirmar:

\begin{abstract}
A AD, tal como a entende a Escola Francesa, não é apenas uma disciplina fugaz, nascida da convergência do marxismo, da psicanálise e da lingüística, sob a égide do estruturalismo, devendo desaparecer com essa conjuntura: ela destina-se a filtrar e integrar os movimentos das disciplinas sobre as quais se apóia e, em primeiro lugar, os da lingüística. Isto implica que ela seja capaz de perceber a especificidade de sua própria experiência.
\end{abstract}

Enfim, qualquer que seja a questão dominante da ADI, nela o estudo do léxico ocupa um lugar importante, conforme Maingueneau (1993, p.129), porém, entendemos que a maneira de pensar a articulação entre discurso e sociedade tem de ser constantemente reavaliada, porque os contextos de produção dos textos/documentos/discursos e as teorias do discurso entraram já definitivamente no trabalho dos Indexadores, que não podem ser neutros.

Finalizando com o pensamento de Cunha (1990, p.22), novamente:
A observação do papel da ideologia em AD desmitificou definitivamente a neutralidade do bibliotecário/documentalista e da informação. O bibliotecário tem o seu discurso e produz discursos quando analisa, sintetiza, representa e recupera a informação, independentemente dos seus critérios de objetividade e grau de instrumentalização técnica.

Ao questionar a leitura do bibliotecário como mera adequação a métodos de tratamento de textos, Lucas (2000, p.50), por sua vez, refere-se à divisão de trabalho, apontada por Pêcheux, pela qual os leitores de arquivos atuam conforme duas culturas - a literal e a interpretativa. Nessa linha de raciocínio, a autora infere que o trabalho do bibliotecário encaminha-se de modo a literalizar sentidos, na crença de que a língua reflete o pensamento com exatidão (Lucas, 2000, p.5977) e de que a sua materialidade tem sido subestimada pelos teóricos da indexação, desde abordagens lingüísticas de Cintra (1983); Cunha (1990); Lara (1993) apud Lucas (2000), chegando às de tratamento informático Baranow (1983) apud Lucas (2000) . Acredita a autora que o método de leitura do bibliotecário, "não garante a equivalência de sentido entre o texto-fonte e a sua representação (os termos selecionados como assunto para a teoria da indexação). As operações de análise e síntese para fins de Análise Documentária estão sujeitas a muitos outros fatores para além daqueles que uma metodologia possa disciplinar, administrar, conter" (Lucas, 200, p.63).

Embora saibamos que a informação documentária não existe à priori, mas é resultado da segmentação de conteúdos feita a partir de hipóteses de organização e que tais formulações variam histórica e funcionalmente, a recuperação de textos feita com base na freqüência e na ocorrência de termos também não caracteriza uma segmentação do tipo classificatório, já que o recorte é pulverizado para as palavras retidas no processo de extração. Para Lara (2002, p. 134) os tesauros representam uma das formas mais consistentes de apresentar uma proposta de organização de um domínio, já que são formulados segundo princípios lógico-semânticos por meio dos quais é possível constituir um todo significativo. Todavia as normas não dizem como encontrar as referências para sedimentar o processo de identificação e de relacionamento entre os termos, razão pela qual há muitos tesauros que o são apenas no nome, pois não formulam claramente 
os vértices a partir dos quais devem ser organizados os termos e os tesauros terminológicos, por exemplo, são instrumentos que usam simultaneamente princípios de organização de tesauros e de organização de sistemas de conceitos. A terminologia teórica e concreta permite fundamentar a delimitação de domínios e a operação de seleção dos termos que lhe são próprios.

Por suas funções, os tesauros têm sido considerados "formas de controle do discurso", enquanto os descritores "são sentidos cristalizados, homogeneizados, sedimentados". A tarefa de indexar implicaria, portanto, circunscrever os sentidos, prescritos no tesauro - "grade interpretativa" (Lucas, 2000, p.71).

Essa grade interpretativa, considerada um sistema de conceitos ou unidades de conhecimento, por sua vez denotados pelos termos e explicados pelas definições, também se relaciona a conjuntos mais abrangentes de idéias ou conceitos, denominados categorias, cuja estrutura faz parte da Teoria da Classificação e da Teoria Geral da Terminologia. Nessa estrutura destacam-se relações lógicas (relação genérico-específica, relação analítica e relação de oposição); relações ontológicas (relação partitiva, relação de sucessão e relação material-produto); relações de efeito (relação de causalidade, relação instrumental e relação de descendência) e relações de equivalência.

A trajetória metodológica da construção dos tesauros requer, portanto, o reconhecimento dessa estrutura complexa de conceitos e relações e a capacidade de controlar ou reordenar significados com base em conhecimentos lógicos e filosóficos, padrões e informações, de modo a permitir ao usuário (indexador ou pesquisador) encontrar os termos mais significativos e relevantes para representar a idéia ou o conceito procurado. Não nos esqueçamos, no entanto, do pensamento de Otlet (1934), no começo do século passado, que dizia: "O pensamento não conhece tudo, a linguagem não expressa tudo, o documento não registra tudo". E os discursos? Diríamos que não se relacionam com exemplos de gramática, mas, sim, com arquivos e seus "senhores da memória ou do esquecimento" (Le Goff, 2003).

\section{REFER Ê N C I A S}

ALCAIDE, G.S. et al. Análise comparativa e de consistência entre representações automática e manual de informações documentárias. Transinformação, v.13, n. 1, p.23-41, 2001.

ARANHA, M.L.A.; MARTINS, M.H.P. Ideologia. In: Filosofando: introdução à filosofia. 2.ed. São Paulo: $\overline{M o d e r n a}$, 1995. p.34-53.

ASSOCIAÇÃO BRASILEIRA DE NORMAS TÉCNICAS. NBR12676/92: Documento. Rio de Janeiro, 1992.

BECCARI, A. J. DRT e aplicativos. In: EVENTO DE INICIAÇÃO CIENTÍFICA (EVINCI), 1 1. Anais... Curitiba: UFPR/PRPPG, 2003. p.112.

CASTRO, C. Cavalo de Tróia. In: Dicionário de mitologia greco-romana. 2.ed. São Paulo: Abril, 1976. p.31.

CUNHA, I.M.R.F. Do mito à análise documentária. São Paulo: USP, 1990. 163p. (Teses; v. 11)

FOUCAULT, M. A arqueologia do saber. Petrópolis: Vozes, 1971.

GADET, F.; HAK, T. (Orgs.) Por uma análise automática do discurso: uma introdução à obra de Michel Pêcheux. 2.ed. Campinas, UNICAMP, 1993. 319p. (Coleção Repertórios).

GARDIN, J.C. Les analyses dês discours. Neuchâtel: Delachaux et Niestlé, 1974.
GUIMARÃES, E. A articulação do texto. São Paulo: Ática, 1990. 87p. (Série princípios).

HENRY, P. Os fundamentos teóricos da análise automática do discurso de Michel Pêcheux (1969). In: GADET, F.; HAK, T. (Org.) Por uma análise automática do discurso: uma introdução à obra de Michel Pêcheux. 2.ed. Campinas: UNICAMP, 1993. p.13-38. (Coleção repertórios).

INTERNATIONAL STANDARDS ORGANIZATION. ISO214-1976 (F), num. 2 - Definiciones: analyse. Genéve, 1976.

IZQUIERDO ARROYO, J.M. De la semiótica del discuro a la semiótica documental. In: . MOREIRO GONZÁLEZ, J.A. Aplicación de las ciências: del texto al resumen documental. Madrid: Universidad Carlos III de Madrid; Boletin Oficial Del Estado, 1993. p.199-225.

KOBASHI, N.Y. Classificação e indexação. Curitiba : Curso de Mestrado Interinstitucional PUC-Campinas e UFPR, 2001. Apontamentos de aulas.

LARA, M.L.G. O processo de construção da informação documentária e o processo de conhecimento. Perspect. Cienc. Inf., v.7, n.2, p.127-139, 2002.

LE GOFF, J. Historia e memória. 5. ed. Campinas: UNICAMP, 2003. $541 \mathrm{p}$. 
LUCAS, C.R. Leitura e interpretação em biblioteconomia. Campinas: UNICAMP, 2000. 91 p. (Coleção pesquisas).

MAINGUENAU, D. Novas tendências em análise do discurso. 2.ed. Campinas: Pontes: UNICAMP, 1993. 198p. (Linguagem Crítica).

MARCHIORI, P.Z. A ciência e a gestão da informação: compatibilidades no espaço profissional. Caderno de Pesquisas em Administração, v.09, n.1, p.91-101, 2002.

MARTINS, G.A.; LINTZ, A. Guia para elaboração de monografias e trabalho de conclusão de curso. São Paulo: Atlas, 2000. p.55-56

MCGARRY, K.J. Armazenamento e recuperação de informações na sociedade. In: _. O conceito dinâmico da informação: uma análise introdutória. Brasília: Briquet de Lemos/Livros, 1999. p.111-140.

ORLANDI, E.P. Leitura \& discurso. São Paulo: Cortez, 1988.

ORLANDI, E.P. A linguagem e seu funcionamento: as formas do discurso. 4.ed. Campinas: Pontes, 1996.
OTLET, P. Traité de documentation: le livre sur le livre; théorie et pratique. Bruxelles: Mundaneum, 1934.

PÊCHEUX, M. Análise automática do discurso (AAD-69) - parte I e Il. In: GADET, Françoise; HAK, Toni. (Org.). Por uma análise automática do discurso: uma introdução à obra de Michel Pêcheux. 2.ed. Campinas: UNICAMP, 1993. p.61-145. (Coleção Repertórios).

PEREIRA, E.C.; BUFREM, L.S. Princípios de organização e representação de conceitos em linguagens documentárias. Encontros Bibli, n. 20, 2005.

PILLON, M.A.; CRUZ, M.A.L. Leitura e discurso científico. Transinformação, Campinas, v.8, n.3, p. 1-7, 1996.

SALOMON, D.V. Aperfeiçoamento da leitura. In: Como fazer uma monografia. 2. ed. São Paulo: Martins Fontes, 1991. p. 37-64.

VÁLIO, E.B.M.; OLIVEIRA, V.F.F. Terminologia da Ciência da Informação: abordagem da análise do discurso. Perpect. Cienc. Inf., v.8, n.2, p.114-133, 2003. 